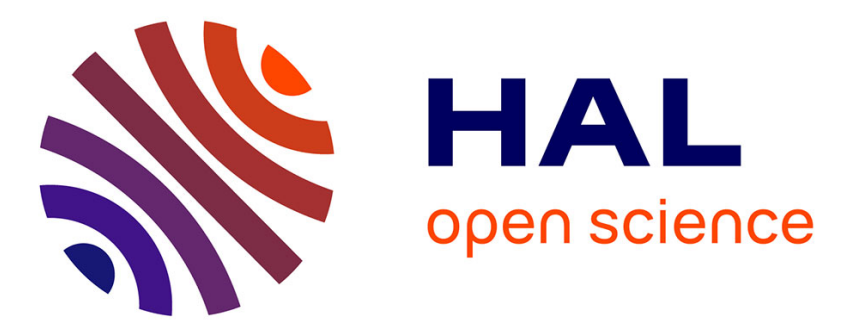

\title{
Design, realization and characterization of silicon nanowire ion sensitive field effect transistors
}

Ahmet Lale, Auriane Grappin, Emmanuel Scheid, Jérôme Launay, Pierre Temple-Boyer

\section{- To cite this version:}

Ahmet Lale, Auriane Grappin, Emmanuel Scheid, Jérôme Launay, Pierre Temple-Boyer. Design, realization and characterization of silicon nanowire ion sensitive field effect transistors. IEEE Nanotechnology Materials and Devices Conference, IEEE NMDC 2016, Oct 2016, Toulouse, France. 2p., 10.1109/NMDC.2016.7777159 . hal-01871410

\author{
HAL Id: hal-01871410 \\ https://hal.laas.fr/hal-01871410
}

Submitted on 10 Sep 2018

HAL is a multi-disciplinary open access archive for the deposit and dissemination of scientific research documents, whether they are published or not. The documents may come from teaching and research institutions in France or abroad, or from public or private research centers.
L'archive ouverte pluridisciplinaire HAL, est destinée au dépôt et à la diffusion de documents scientifiques de niveau recherche, publiés ou non, émanant des établissements d'enseignement et de recherche français ou étrangers, des laboratoires publics ou privés. 


\title{
Design, realization and characterization of silicon nanowire ion sensitive field effect transistors
}

\author{
Ahmet LALE ${ }^{1}$, Auriane GRAPPIN ${ }^{1}$, Emmanuel SCHEID ${ }^{1}$, Jérôme LAUNAY ${ }^{1}$, Pierre TEMPLE- \\ BOYER $^{1}$
}

\author{
${ }^{1}$ LAAS-CNRS, Université de Toulouse, F-31031 Toulouse, France
}

\begin{abstract}
The aim of our research project is to achieve a potentiometric multi-sensor platform, consisting of ion sensitive field effect transistors ISFET and MOSFET, which channel is a nanowire or a network of horizontal Silicon nanowires and whose gate insulator is alumina $\mathrm{Al}_{2} \mathrm{O}_{3}$ deposed by Atomic Layer deposition ALD. This microdevice will provide chemical and biological analyses in the liquid phase, in microfluidic channels.
\end{abstract}

\section{INTRODUCTION}

Ion sensitive field effect transistors are microsensors derived by metal oxide semiconductor field effect transistors [1]. These are electronic microsensors designed to measure the $\mathrm{pH}$. ISFETs have been functionalized for many applications such as the measurement of potassium [2], sodium [2], ammonium [3], urea [4], creatinine [5], lactate [6], glutamate [7] ...

Today, to open the door to new innovative applications, it is necessary to increase the sensitivity, decrease response times and detection limit of ISFET. To meet this challenge, the transistor based on silicon nanowires with surrounding gate seems to be the ideal candidate: low channel dimensions allow to work in micro-volume and thus to reduce the amount of analyte. But the biggest advantage lies in being able to work at the single living cell level. Moreover, the atomic layer deposition (ALD) now allows to achieve, for these nanoISFETs, controlled nanometric thickness gate insulators with adequate quality in terms of defects.

\section{STUDY OF ALD ALUMINA}

To achieve the gate insulator of our transistors, we have chosen to replace the silicon nitride $\mathrm{Si}_{3} \mathrm{~N}_{4}$, previously used for the ISFETs in our past studies, by alumina $\mathrm{Al}_{2} \mathrm{O}_{3}$ which provides better sensitivity [8], which is a better insulator in liquid phase [8] and allows to be more selective against sodium and potassium than silicon nitride [8]. We chose to deposit the alumina through the ALD. The advantage of this technique is to deposit extremely compliant films and whose thicknesses are controlled close to the molecular monolayer [9]. The principle is to make successively reacting precursors, directly on the substrate's surface. A successive reaction of the precursors creates a molecular monolayer of alumina and this cycle is repeated $n$ times according to the desired thickness. The first work was to make alumina films from 100 ALD cycles $(\sim 11 \mathrm{~nm})$ to 600 ALD cycles $(\sim 54 \mathrm{~nm})$ to study the deposition kinetic. Figure 1 shows the evolution of the average thickness (measured by ellipsometry) deposed by each ALD cycle to measure the deposition velocity. We compared the evolution of the refractive index of these deposits (figure 1) and we have highlighted a correlation between the refractive index and the deposition kinetic.

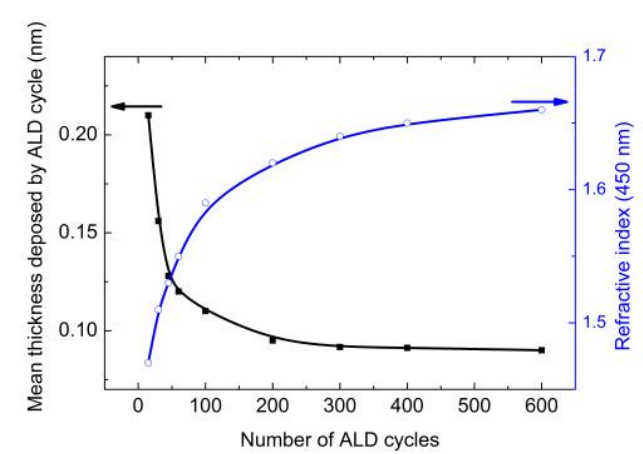

Figure 1 : evolution of refractive index and average thickness deposited by each ALD cycle based on the total number of completed ALD cycles.

Previously we obtained a 40nm deposit, with a refractive index of 1.65 , a bit too low, the refractive index of the massive alumina being 1.78 without extinction coefficient [10]. To improve refractive index of our material, we did a thermal annealing campaign of 5 minutes under $\mathrm{N}_{2} / \mathrm{H}_{2}$ and we were significantly closer to the refractive index of the massive alumina (figure 2), on the other hand, we measured an extinction coefficient, that we explain by deficiencies in oxygen that appear in our material with the temperature rise. So, we decided to make our post-deposition annealing under $\mathrm{O}_{2}$ and we have improved the index of refraction as previously (figure 2) while keeping a null extinction coefficient.

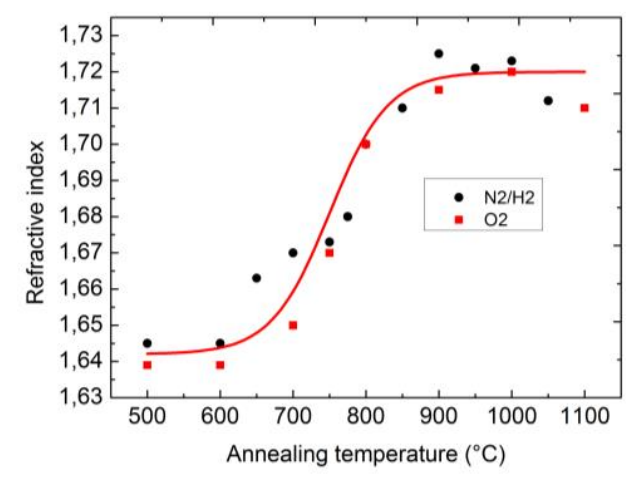

Figure 2 : changes in refractive index of alumina according to the postdeposition annealing temperature.

An X-ray diffraction study of ALD $\mathrm{Al}_{2} \mathrm{O}_{3}$ showed that alumina films are amorphous after deposition, but they crystallize when they are annealed up to $750^{\circ} \mathrm{C}$. It shows that a structural modification of alumina induces the optical index improvement.

We have made MIS capacitors (metal insulator semiconductor) with the alumina as an insulator, to electrically characterize the ALD deposition. With $\mathrm{C}(\mathrm{V})$, we 
noticed that the flat-band voltage decreases with annealing temperature, which means that it lowers the number of charges in insulator (figure 3). The accumulation capacity increases as well as the dielectric constant from 8.5 for nonannealed layers to 10 for layers annealed at $900^{\circ} \mathrm{C}$ (figure 4), conform to the literature of massive alumina [11].
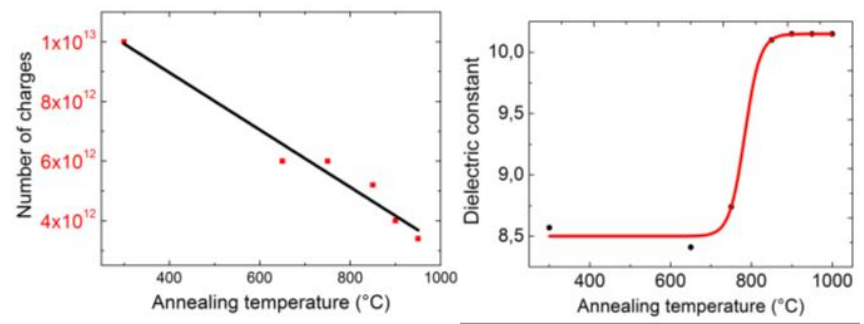

Figure 3 : left, number of charges in the insulator according to the annealing temperature under $\mathrm{O}_{2}$.

Right, dielectric constant depending on the annealing temperature under $\mathrm{O}_{2}$.

\section{NANOISFET STRUCTURE}

We used, on 6 inch SOI wafers, the projection photolithography with a resolution lower than $250 \mathrm{~nm}$, less than the maximum resolution of used Canon FPA-3000i4 stepper (350nm) and photoresist AZ ECI 3012, (400nm). After optimizations, we have managed to achieve on a single chip, with the same insolation parameters, transistors with a single nanowire as channel, next to transistors with 100 nanowires parallel network. The goal is to eventually compare in liquid phase, the pros and cons of each structure. We obtained reproducibly nanowires width less than $200 \mathrm{~nm}$. Once photoresist nanowires were optimized, we transferred them into silicon thanks to a reactive ion etching. Source and drain areas were $\mathrm{N}$ doped with arsenic. Then comes the realization of the gate insulator with alumina after RCA cleaning process (figure 4).

Once the transistors and interconnections ended (figures 4), we realized covered fluidic channels, using the SU8-3D technique [12], which has been optimized for $5 \mu \mathrm{m}$ wide channels (figure 5).

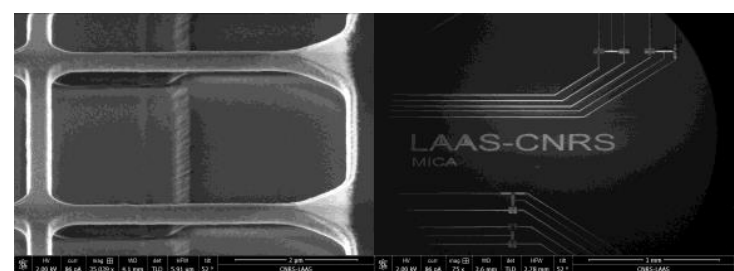

Figure 4 : left, silicon nanowires, after gate insulator completion. right nanoMOSFET and nanoISFET with interconnections.

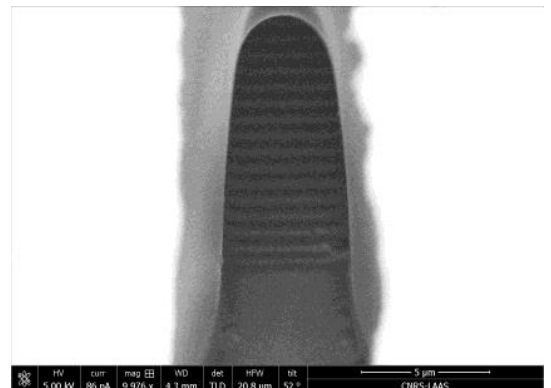

Figure 5: dense nanowire network in a SU8 microfluidic channel, after removing the cover through a FIB etching.

Firstly, concerning MOSFET characterizations, we obtained very low subthreshold current: $10^{-14} \mathrm{~A}$ for $\mathrm{Vg}=2 \mathrm{~V}$ and low leakage currents through the gate (figure 6).

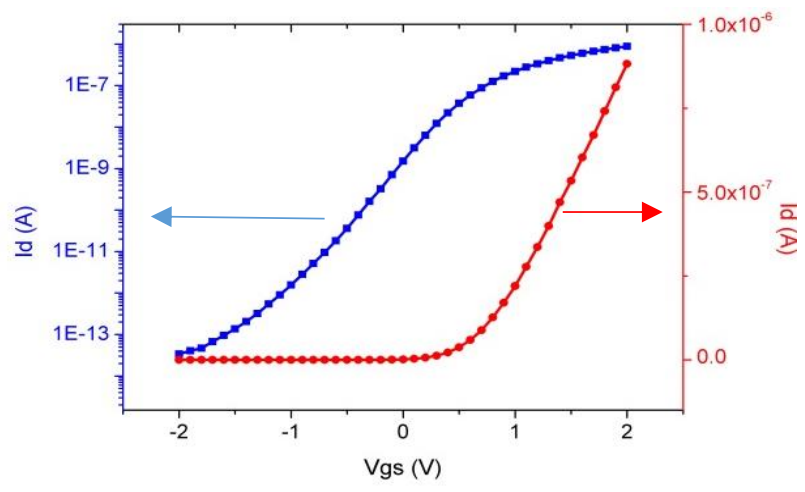

Figure $6: \mathrm{I}(\mathrm{V})$ characterization of a nanoMOSFET, red with a linear scale and blue with a semi-logarithmic scale. $\left(\mathrm{V}_{\mathrm{DS}}=0.1 \mathrm{~V}\right)$

We have then characterized nanoISFETs in liquid phase, and as for the MOS transistors, we got excellent characteristics, with extremely low leakage currents through gate insulator $\left(10^{-12} \mathrm{~A}\right.$ for $\left.\mathrm{Vg}=2 \mathrm{~V}\right)$. Subthreshold Id current is also excellent. In addition, we have a good response to the $\mathrm{pH}$ variations (figure 7).

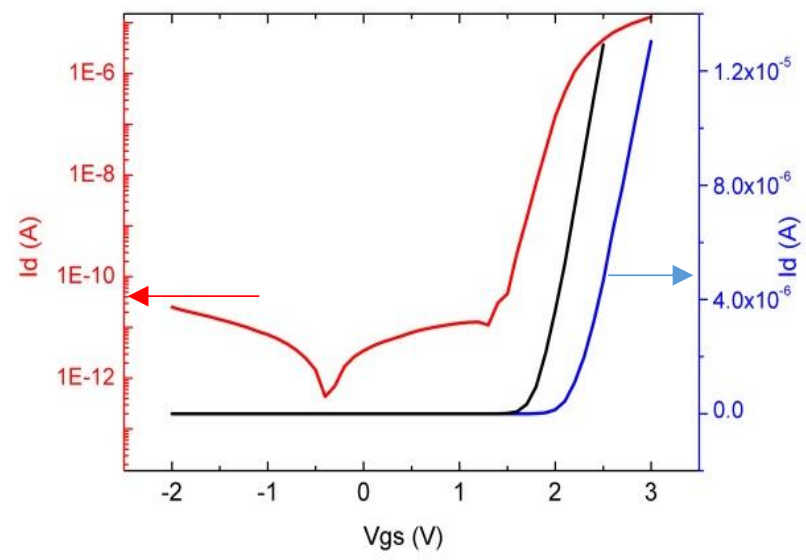

Figure 7 : I(V) characterization of a nanoISFET, in black $\mathrm{pH} 4, \mathrm{pH} 7$ in blue, red at $\mathrm{pH} 7$ with a semi-logarithmic scale. $\left(\mathrm{V}_{\mathrm{DS}}=0.1 \mathrm{~V}\right)$

\section{CONCLUSION}

We studied alumina deposed by ALD and we have demonstrated that it is possible to improve its physical and dielectric characteristics using thermal annealing under oxygen. We then realized nanoMOSFETs and nanoISFETs using alumina as gate dielectric. The first $\mathrm{pH}$ characterizations made in liquid medium are very encouraging for the future, with the perspective of the study of single living cells.

\section{REFERENCES}

[1] Bergveld, P. IEEE Transactions on Biomedical Engineering BME17, 70-71 (1970)

[2] Hajji, B. et al. Microelectronics Reliability 40, 783-786 (2000).

[3] Humenyuk, I. et al. Microelectronics Journal 37, 475-479 (2006).

[4] Temple-Boyer, P. et al. Sensors and Actuators B: Chemical 131, 525532 (2008).

[5] Sant, W. et al. Sensors and Actuators B: Chemical 103, 260-264 (2004).

[6] Diallo, A. K. et al. Biosensors and Bioelectronics 40, 291-296 (2013).

[7] Djeghlaf, L. (Université Paul Sabatier - Toulouse III, 2013).

[8] Matsuo, T. \& Esashi, M. Sensors and Actuators 1,77-96 (1981).

[9] Puurunen, R. L. Chem. Vap. Deposition 20, 332-344 (2014).

[10] Malitson, I. H. Journal of the Optical Society of America 52, 1377 (1962).

[11] Khalid Z. Rajab J. Micro. and Elect. Pack. 5, 101-106 (2008).

[12] Larramendy, F. et al. Lab Chip 12, 387-390 (2011). 